\title{
Short-term Change in Resting Energy Expenditure and Body Compositions in Therapeutic Process for Graves' Disease
}

\author{
Akinori Hayashi ${ }^{1}$, Koji Takano ${ }^{1}$, Yuko Kawakami ${ }^{2}$, Mamiko Hitomi ${ }^{2}$, Yasuhiro Ohata ${ }^{1}$, \\ Agena Suzuki ${ }^{1}$, Yuji Kamata ${ }^{1}$ and Masayoshi Shichiri ${ }^{1}$
}

\begin{abstract}
:
Objective In the medical treatment of Graves' disease, we sometimes encounter patients who gain weight after the onset of the disease. To estimate the energy required during the course of treatment when hyperthyroidism ameliorates, we measured the resting energy expenditure (REE) and body composition in patients with Graves' disease before and during treatment in the short-term.

Methods Twenty patients with newly diagnosed Graves' disease were enrolled, and our REE data of 19 healthy volunteers were used. The REE was measured by a metabolic analyzer, and the basal energy expenditure (BEE) was estimated by the Harris-Benedict formula. The body composition, including body weight, fat mass (FM), muscle mass (MM) and lean body mass (LBM), were measured by a multi-frequency body composition analyzer. We tailored the nutritional guidance based on the measured REE.

Results Serum thyrotropin levels were significantly increased at three and six months. Serum free thyroxine, free triiodothyronine and REE values were significantly decreased at one, three and six months. The REE/BEE ratio was $1.58 \pm 0.28$ at the onset and significantly declined to $1.34 \pm 0.34,1.06 \pm 0.19$ and $1.01 \pm 0.16$ at 1,3 and 6 months, respectively. Body weight, MM and LBM significantly increased at three and six months.

Conclusion The REE significantly decreased during treatment of Graves' disease. The decline was evident as early as one month after treatment. The REE after treatment was lower than in healthy volunteers, which may lead to weight gain. These data suggest that appropriate nutritional guidance is necessary with shortterm treatment before the body weight normalizes in order to prevent an overweight condition and the emergence of metabolic disorders.
\end{abstract}

Key words: Graves' disease, resting energy expenditure, resting metabolic rate, hyperthyroidism

(Intern Med 59: 1827-1833, 2020)

(DOI: 10.2169/internalmedicine.4462-20)

\section{Introduction}

Graves' disease is an autoimmune thyroid disease that induces thyrotoxicosis. Graves' disease patients often lose weight due to increased energy expenditure and calorigenesis that exceeds the calorie intake, which is usually increased in these patients (1-3). During the course of treatment, when the serum thyroid hormone level normalizes, the energy expenditure and basal metabolic rate decrease, which often results in body weight gain (4-7). Therefore, it is necessary to start nutritional guidance early in the course of treatment to prevent excessive body weight gain and the emergence of metabolic disorders. However, few studies have evaluated the increase in energy expenditure at the onset and the changes in energy expenditure and body composition of Graves' disease, especially in the short term after the start of treatment, in a large number of cases.

${ }^{1}$ Department of Endocrinology, Diabetes and Metabolism, Kitasato University School of Medicine, Japan and ${ }^{2}$ Department of Nutrition, Kitasato University Hospital, Japan

Received for publication January 10, 2020; Accepted for publication March 13, 2020

Correspondence to Dr. Akinori Hayashi, ahayashi@kitasato-u.ac.jp 
We hypothesized that the REE changes dramatically in the short-term after treatment in patients with Graves' disease, which may lead to weight gain after treatment. The aim of this study was to measure the changes in the REE and body composition in patients with Graves' disease during the course of treatment.

\section{Materials and Methods}

\section{Study design and participants}

This study was a preliminary prospective study approved by the Ethics Committee of Kitasato University Hospital, and all patients gave their written informed consent. All patients were newly diagnosed with Graves' disease between October 2012 and March 2014 at Kitasato University Hospital and did not meet any of the exclusion criteria (any condition that affects energy expenditure, such as diabetes mellitus or severe hepatic disease, kidney disease, malignant disease, infectious disease, exothermic disease, taking medicine including glucocorticoids, and pregnancy). The diagnosis of Graves' disease was based on elevated serum free thyroxine (FT4; reference range $1.00-1.80 \mathrm{ng} / \mathrm{dL}$ ) and free triiodothyronine (FT3; reference range 2.30-4.00 pg/mL) levels with a suppressed serum thyrotropin (TSH; reference range 0.27-4.20 $\mu \mathrm{IU} / \mathrm{mL}$ ) level and positive antithyroid antibody, TSH receptor antibody (TRAb) and/or TSH-stimulating antibody (TSAb).

To achieve a difference in the $\triangle$ REE, a sample size of $n=$ 7 patients with Graves' disease was required to achieve $90 \%$ power with type 1 error of 0.05 . We planned to gather a sample size of 20 patients with Graves' disease. When we performed blood test at the first visit and diagnosed Graves' disease, we explained the details of this study to the patients. We measured the REE on the same day in patients who agreed and started treating their Graves' disease. During the course of treatment, blood samples were drawn, and the REE was measured at the first visit and each visit at one, three and six months.

\section{Biochemical measurements}

Serum FT4, FT3 and TSH levels as well as TRAb were measured with an electrochemiluminescent immunoassay (Cobas8000 and Modular Analytics EE, Roche Diagnostic, Tokyo, Japan). TSAb was measured with a bioassay radioimmunoassay (TSAb kit Yamasa; Yamasa, Chiba, Japan). The normal ranges of TRAb and TSAb are $<2.00 \mathrm{IU} / \mathrm{L}$ and $<180 \%$, respectively.

\section{Energy expenditure and metabolic measurements}

The REE and body composition were measured on the same day as the diagnosis of Graves' disease, before antithyroid drug was started (at the onset), and again at one, three and six months after treatment for hyperthyroidism. The REE was measured by a metabolic analyzer $\left(\right.$ MedGem $^{\circledR}$, Microlife Medical Home Solution, Golden,
USA) after at least four hours of fasting at all points. The measurement was performed in a seated position in a room (temperature $22-26^{\circ} \mathrm{C}$ ) after staying in the same room for at least $20 \mathrm{~min}$. The basal body expenditure (BEE) was calculated by the Harris-Benedict formula (8) as follows: $66.47+$ $(13.75 \times \mathrm{W})+(5 \times \mathrm{H})-(6.75 \times \mathrm{A})$ for men and $665.1+(9.563 \times \mathrm{W})+$ $(1.85 \times \mathrm{H})-(4.676 \times \mathrm{A})$ for women, with $\mathrm{W}$ equal to weight in kilograms, $\mathrm{H}$ the height in centimeters and $\mathrm{A}$ the age in years. The body composition, including the body weight, fat mass (FM), muscle mass (MM) and lean body mass (LBM), were measured by a body composition analyzer using the latest 8-electrode multi-frequency technology (body composition analyzer MC 180; Tanita, Tokyo, Japan). Patients stood with the ball and heel of each foot in contact with electrodes on the floor scale after urination. Once the weight was recorded, patients were instructed to grasp the hand grips and hold them down by their sides with metabolic electrodes in contact with the palm and thumb. Arms were extended and kept away from the body according to the manufacturer's instructions (9).

The coefficient of variance of the impedance measurement was reported as $0.4 \%$ (10). Nutritional guidance based on the REE [daily calorie intake between 1.3- and 1.5-fold the REE, using the activity factor, which is a mild activity level $(8,11,12)]$ was provided to each patient during the study.

\section{Statistical analyses}

All data are presented as the mean \pm standard deviation (SD), unless otherwise indicated. All changes in variables within patients (onset-after) were analyzed by a one-way analysis of variance (ANOVA) and Kruskal-Wallis test and then Wilcoxon's signed-rank signed rank test when significant. All changes in variables were compared with healthy volunteers by the Mann-Whitney $U$ test. To determine the relationships, single linear regression analyses were employed. $\mathrm{p}<0.05$ was considered significant. Statistical analyses were performed using the GraphPad Prism 5.02 software program (GraphPad Software, San Diego, USA).

\section{Results}

\section{Demographic and clinical characteristics of the en- rolled participants}

The demographic and clinical characteristics of the enrolled patients are shown in Table. Twenty patients with newly diagnosed Graves' disease (14 women and 6 men, median age 40 years old) were enrolled in this study. A total of 19 age- and sex-matched healthy volunteers (16 women and 3 men, median age 31 years old) were extracted from our REE data of healthy volunteers. None of the healthy volunteers had any current medical problems. Eleven patients were initially treated with thiamazole alone, seven with thiamazole and propranolol, one with thiamazole and potassium iodide and one with potassium iodide alone. Be- 
Table. Characteristics of the Enrolled Patients.

\begin{tabular}{lcccc}
\hline \multicolumn{1}{c}{ Variable } & Onset & $1 \mathrm{M}$ after & $3 \mathrm{M}$ after & $6 \mathrm{M}$ after \\
\hline Gender (male/female) & $6 / 14$ & & & \\
Age (years) & $40.0(18-78)$ & & & \\
Height $(\mathrm{cm})$ & $160.3 \pm 8.2$ & & & \\
Body weight $(\mathrm{kg})$ & $54.0 \pm 11.9$ & $53.0 \pm 9.0^{*}$ & $56.0 \pm 11.0^{\dagger}$ & $56.8 \pm 11.8^{\dagger}$ \\
BMI $\left(\mathrm{kg} / \mathrm{m}^{2}\right)$ & $20.9 \pm 3.2$ & $20.7 \pm 2.4^{*}$ & $21.8 \pm 3.1^{\dagger}$ & $22.3 \pm 3.1^{\dagger}$ \\
FM $(\mathrm{kg})$ & $14.0 \pm 7.4$ & $14.3 \pm 5.7^{* *}$ & $14.6 \pm 7.0$ & $15.9 \pm 8.1$ \\
MM $(\mathrm{kg})$ & $38.3 \pm 8.4$ & $37.9 \pm 7.6$ & $39.8 \pm 8.1^{* *}$ & $42.0 \pm 8.1^{*}$ \\
LBM $(\mathrm{kg})$ & $40.4 \pm 8.9$ & $40.1 \pm 7.9$ & $42.1 \pm 8.5^{* *}$ & $44.4 \pm 8.5^{*}$ \\
BEE $(\mathrm{kcal} / \mathrm{day})$ & $1,293 \pm 228$ & $1,295 \pm 195$ & $1,346 \pm 249$ & $1,346 \pm 264$ \\
REE $(\mathrm{kcal} / \mathrm{day})$ & $2,059 \pm 578$ & $1,716 \pm 495^{* *}$ & $1,428 \pm 356^{\dagger \dagger}$ & $1359 \pm 308^{\dagger \dagger}$ \\
REE/BEE & $1.58 \pm 0.28$ & $1.34 \pm 0.34^{\dagger}$ & $1.06 \pm 0.19^{\#}$ & $1.01 \pm 0.16^{\dagger \dagger}$ \\
TSH $(\mu \mathrm{IU} / \mathrm{mL})$ & $<0.01$ & $0.01(<0.01-0.02)$ & $0.59(0.01-20.55)^{\dagger}$ & $1.59(0.01-21.65)^{\#}$ \\
FT3 $(\mathrm{pg} / \mathrm{mL})$ & $18.93 \pm 9.79$ & $6.49 \pm 3.29^{\#}$ & $2.92 \pm 0.75^{\#}$ & $3.27 \pm 1.21^{\#}$ \\
FT4 $(\mathrm{ng} / \mathrm{dL})$ & $5.45 \pm 2.07$ & $2.14 \pm 1.06^{\#}$ & $0.91 \pm 0.33^{\#}$ & $1.15 \pm 0.33^{\#}$ \\
LDL-C $(\mathrm{mg} / \mathrm{dL})$ & $68.1 \pm 17.5$ & $92.3 \pm 17.3^{\#}$ & $111.1 \pm 32.7$ & $108.5 \pm 21.0$ \\
HDL-C $(\mathrm{mg} / \mathrm{dL})$ & $58.9 \pm 13.8$ & $68.1 \pm 16.7^{\dagger}$ & $69.4 \pm 14.4^{\dagger}$ & $66.6 \pm 13.0^{\#}$ \\
TG $(\mathrm{mg} / \mathrm{dL})$ & $85.9 \pm 29.8$ & $113.9 \pm 37.9^{*}$ & $85.8 \pm 27.4$ & $82.6 \pm 43.9$ \\
\hline
\end{tabular}

Data are Mean \pm SD or Median (minimum-maximum).

*: $\mathrm{p}<0.05,{ }^{*}: \mathrm{p}<0.01,{ }^{\dagger}: \mathrm{p}<0.005,{ }^{\dagger \dagger}: \mathrm{p}<0.001,{ }^{\#}: \mathrm{p}<0.0005,{ }^{\# \#}: \mathrm{p}<0.0001 \mathrm{vs}$. Onset analyzed by Wilcoxon signedrank signed rank test when Kruskal-Wallis test was significant.

BMI: body mass index, FM: fat mass, MM: muscle mass, LBM: lean body mass, BEE: basal energy expenditure, REE: resting energy expenditure, TSH: thyrotropin, FT3: free triiodothyronine, FT4: thyroxine, LDL-C: low-density lipoprotein cholesterol, HDL-C: high-density lipoprotein cholesterol, TG: triglyceride

fore the onset of Graves' disease, 3 patients (15\%) showed a low body mass index (BMI) under $18.5 \mathrm{~kg} / \mathrm{m}^{2}$, and $4(20 \%)$ showed a high BMI over $25.0 \mathrm{~kg} / \mathrm{m}^{2}$. Fifteen patients $(75 \%)$ had experienced weight loss before the initial visit. None met the criteria of dyslipidemia defined by low-density lipoprotein cholesterol $\geq 140 \mathrm{mg} / \mathrm{dL}$, triglyceride $\geq 150 \mathrm{mg} / \mathrm{dL}$ or high-density lipoprotein cholesterol $<40 \mathrm{mg} / \mathrm{dL}$. Two patients dropped out of the clinical trial (one at one month and the other at three months).

\section{The correlation between thyroid hormones and en- ergy expenditure}

The REE was significantly correlated with TSH, FT3 and FT4 $(\mathrm{r}=-0.26, \mathrm{p}<0.05 ; \mathrm{r}=0.60, \mathrm{p}<0.0001 ; \mathrm{r}=0.63, \mathrm{p}<0.0001$, respectively) (Fig. 1A-C). There was also a significant correlation between the REE/BEE ratio and TSH, FT3 and FT4 $(\mathrm{r}=-0.35, \mathrm{p}<0.005 ; \mathrm{r}=0.68, \mathrm{p}<0.0001 ; \mathrm{r}=0.72, \mathrm{p}<0.0001$, respectively) (Fig. 1D-F).

\section{Change in the thyroid function during treatment}

The serum TSH level was significantly increased at 3 and 6 months during treatment compared with the onset $(\mathrm{p}<$ 0.005; p<0.0005) (Fig. 2A). Both the serum FT3 and FT4 levels were decreased during treatment at 1,3 and 6 months (all p<0.0005) (Fig. 2B, C). At 3 months, the FT3 level was outside of the normal range in 6 patients (higher in 3 patients and lower in 3 patients), and the FT4 level was outside of the normal range in 10 patients (slightly higher in 1 patient and slightly lower in 9 patients). At 6 months, the FT3 level was outside of the normal range in 3 patients (higher in 2 patients and lower in 1 patient), and the FT4 level was outside of the normal range in 6 patients (slightly higher in 1 patient and slightly lower in 5 patients).

\section{Changes in the energy expenditure in patients with Graves's disease}

In patients with Graves' disease, the mean REE at the onset $(2,059 \pm 578 \mathrm{kcal} /$ day $)$ was significantly higher than the mean BEE $(1,293 \pm 228 \mathrm{kcal} / \mathrm{day})$ calculated by the HarrisBenedict formula $(\mathrm{p}<0.0001)$. The mean REE during treatment significantly decreased to $1,716 \pm 495 \mathrm{kcal} /$ day $(\mathrm{p}<$ $0.01), 1,428 \pm 356 \mathrm{kcal} /$ day $(\mathrm{p}<0.001)$ and $1,359 \pm 308 \mathrm{kcal} /$ day $(\mathrm{p}<0.001)$ at 1,3 and 6 months, respectively, from the value at the onset (Fig. 2D). The mean REE of patients with Graves' disease at the onset was significantly higher $(\mathrm{p}<$ $0.05)$, at 1 and 3 months showed no significant difference, and at 6 months after treatment was significantly lower $(\mathrm{p}<$ $0.01)$ than that in healthy volunteers $(1,606 \pm 269 \mathrm{kcal} / \mathrm{day})$. The mean REE/BEE ratio at the onset was $1.58 \pm 0.28$ and significantly decreased to $1.34 \pm 0.34(\mathrm{p}<0.005), 1.06 \pm 0.19$ ( $\mathrm{p}$ $<0.001)$ and $1.01 \pm 0.16(\mathrm{p}<0.0005)$ at 1,3 and 6 months, respectively, after treatment from the onset (Fig. 2E). The mean REE/BEE of patients with Graves' disease at the onset was significantly higher $(\mathrm{p}<0.0001)$, at 1 and 3 months showed no significant difference, and at 6 months after treatment was significantly lower $(\mathrm{p}<0.01)$ than that in healthy volunteers $(1.17 \pm 0.17)$.

\section{Changes in the body composition and lipid profile}

The body weight and BMI gradually increased during 
A

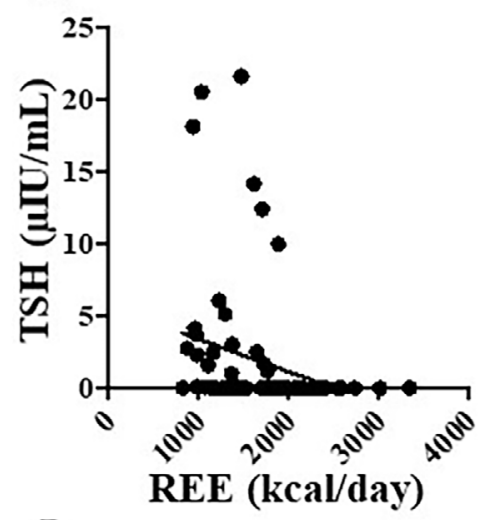

D

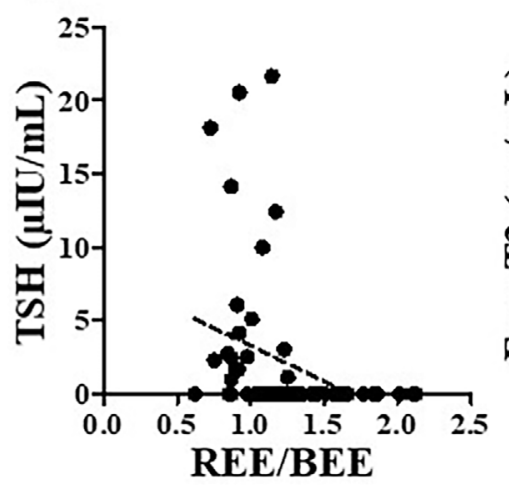

B

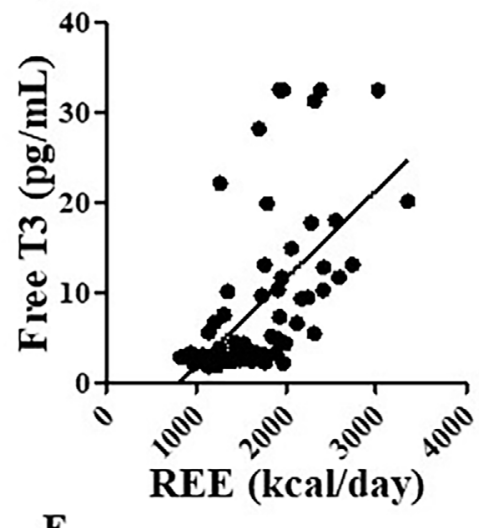

E

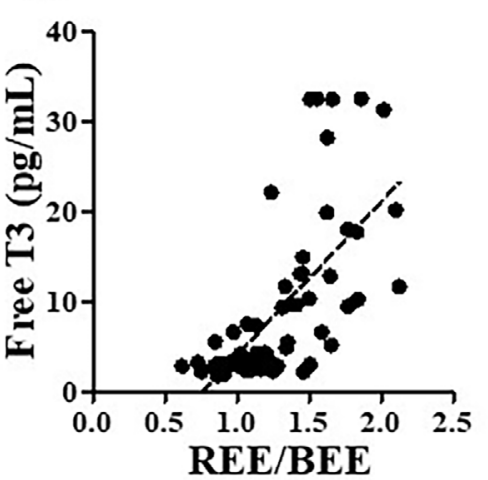

C
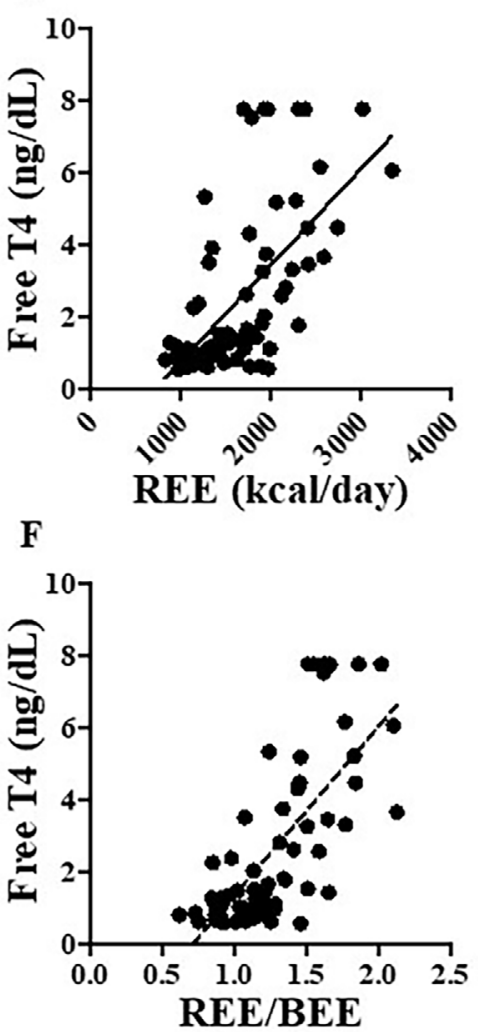

Figure 1. Correlations between the indicators of energy expenditure [REE (A-C) and the REE/BEE ratio (D-F)] and the thyroid function [TSH (A and D), free T3 (B and E) and free T4 (C and F)] are plotted. A linear regression model was used for the analysis. REE: resting energy expenditure, BEE: basal energy expenditure, TSH: thyrotropin, T3: triiodothyronine, T4: thyroxine

treatment (Table). The body weight significantly increased by $0.99 \pm 1.72 \mathrm{~kg}, 3.81 \pm 3.84 \mathrm{~kg}$ and $4.56 \pm 4.60 \mathrm{~kg}$, at 1,3 and 6 months, respectively $(\mathrm{p}<0.05 ; \mathrm{p}<0.005$; $\mathrm{p}<0.005)$ (Table). The BMI also significantly increased during treatment by $0.37 \pm 0.67 \mathrm{~kg} / \mathrm{m}^{2}, 1.46 \pm 1.41 \mathrm{~kg} / \mathrm{m}^{2}$ and $1.75 \pm 1.72 \mathrm{~kg} / \mathrm{m}^{2}$ at 1,3 and 6 months, respectively $(\mathrm{p}<0.05 ; \mathrm{p}<0.001 ; \mathrm{p}<$ $0.005)$ (Table). At 6 months, 7 patients (35\% of all) reached a weight heavier than that before the onset of Graves' disease. The FM was significantly increased at one and three months, while there was no significant increase at six months compared to three months. There was a significant increase in the MM and LBM during treatment (Table). In addition, no patients developed dyslipidemia throughout the course of this study (Table).

\section{Discussion}

In the present study with frequent measurements of REE in the short term after treatment in patients with Graves' disease, we found that the REE dramatically decreased as early as one month after treatment. Thyroid hormone affects energy expenditure and energy balance via several mechanisms, including thermogenesis and other energy expenditure routes (13-15). High levels of thyroid hormone increase oxygen consumption and heat production, resulting in marked body weight loss, while low levels of thyroid hormone decrease the metabolic rate and oxidation of energy substrates, such as lipids, carbohydrates and amino acids (16-19), resulting in body weight gain. In a previous study (20), it was suggested that thyroid hormone increases energy expenditure by uncoupling mitochondrial oxidative phosphorylation. In brown adipose tissue, triiodothyronine produced by iodothyronine deiodinase exerts adaptive energy expenditure during cold exposure. Leptin is involved in the regulation of the appetite and food intake as well as energy storage in the thyrotoxic state (21). However, the relationship between thyroid hormones and serum leptin levels and why an increased appetite persists even after thyroid state normalization remains to be investigated in both humans and rodents $(22,23)$.

The energy expenditure in patients with Graves's disease is unclear, especially in the short term after treatment. Most patients with Graves' disease experience marked body weight loss despite increased dietary intake at the onset of the disease. During treatment, when thyrotoxicosis subsides, decreased energy expenditure with a remaining increased appetite results in an overweight condition and sometimes obesity. In our study, only 1 patient, whose BMI before the onset of the disease was $22.8 \mathrm{~kg} / \mathrm{m}^{2}$, newly became obese $(\geq 25$ $\mathrm{kg} / \mathrm{m}^{2}$ ) at 6 months after treatment, but this patient did not 
A

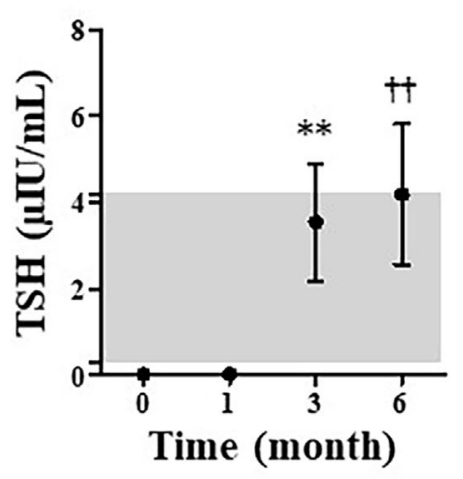

D

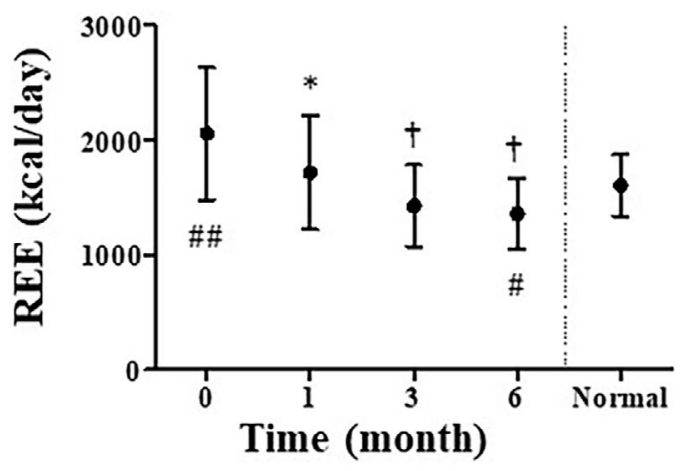

B

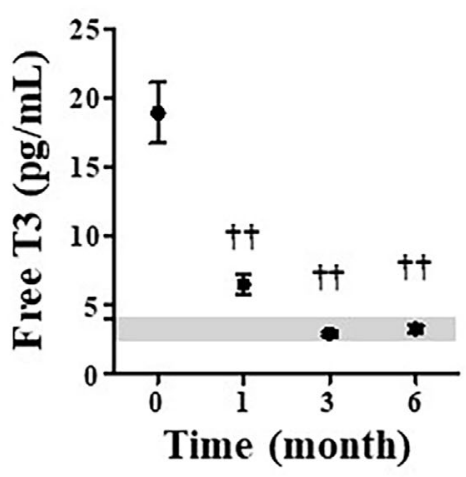

E
C

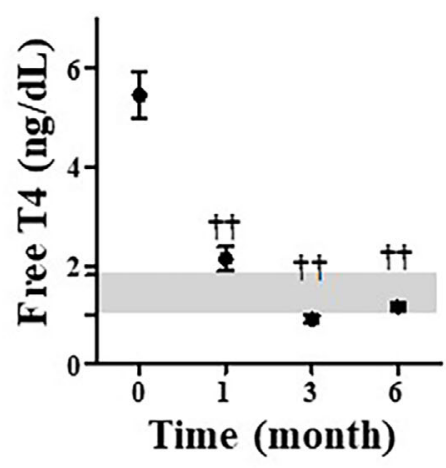

Time (month)

Figure 2. Changes in the thyroid function, the TSH (A), free T3 (B) and free T4 (C), and the indicators of energy expenditure, the REE (D) and REE/BEE ratio (E), during treatment are plotted. Data are shown as the mean \pm SD. $*, \mathbf{p}<0.01 ; * *, \mathbf{p}<0.005 ; \dagger, \mathbf{p}<0.001 ; \dagger \dagger, \mathbf{p}<0.0005$. $\mathrm{P}$ values were corrected according to Wilcoxon's signed-rank test vs. the onset. \#, $\mathbf{p}<0.05$; \#, $\mathbf{p}<0.01$; \#\#, $\mathbf{p}<0.0001$. P values were corrected according to the Mann-Whitney $U$ test vs. healthy controls. TSH: thyrotropin, T3: triiodothyronine, T4: thyroxine, REE: resting energy expenditure, BEE: basal energy expenditure

show hypothyroidism due to overtreatment during the treatment course.

Previous studies in adolescents and adults (24-26) showed that the TSH levels are slightly increased in obese subjects compared to normal-weight subjects during treatment. Slightly elevated TSH levels associated with normal free thyroxine indicate subclinical hypothyroidism. Subclinical hypothyroidism is reported to be associated with overweight, dyslipidemia, ischemic heart disease and mortality (27-33). Some of the patients who become obese after treatment for Graves' disease and remain obese develop metabolic disorders, including an abnormal lipid profile and diabetes mellitus. However, little evidence is available concerning the nutritional requirements during treatment for Graves' disease to prevent the development of obesity.

In a previous study, the REE of patients with thyrotoxicosis was significantly higher than that of healthy controls (34). Similarly, the REE of patients with Graves' disease at the onset was significantly (1.28-fold) higher than that of healthy controls, and 15 patients (75\%) lost body weight at the onset in our study. Because the BEE is calculated by the body weight, the energy expenditure is believed to be negatively affected by the body weight. However, our data showed that patients with Graves' disease gained weight with a decreased thyroid function while the REE decreased. Although patients with Graves' disease before treatment tended to weigh less than normal controls, a higher REE than in normal controls was not an effect of body weight; instead, the energy expenditure was suggested to depend on the pathological condition of hyperthyroidism.

The REE can be estimated using the following formula $\mathrm{REE}=\mathrm{BEE} \times$ stress factor. The stress factor, or the REE/BEE ratio, has been investigated in various diseases and conditions (12), and it reflects the pathology of Graves' disease in our study. Because the BEE was calculated by the weight at each point, the REE/BEE ratio is suggested to have little effect on the body weight and its changes. In our study, the

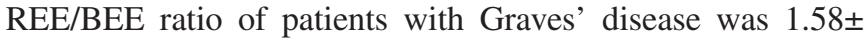
0.28 , indicating the stress factor of Graves' disease with thyrotoxicosis was about 1.6-fold. During treatment, thyroid hormone levels were reduced to normal or near normal at six months. The REE also declined as FT4 levels normalized and reached 1.0-fold at 6 months. Furthermore, the REE at six months after treatment in the patients with Graves' disease was lower than in healthy controls. Therefore, patients with Graves' disease are considered to pro- 
gress to a condition where weight gain tends to increase more than in healthy subjects over the course of treatment. However, most of the patients in our study were aggressively treated at the onset because of severe symptomatic and biochemical hyperthyroidism; as a result, the thyroid function was lower than the reference range in some patients. In the short term after treatment, overtreatment was sometimes shown in patients with severe hyperthyroidism. It should be considered that this overtreatment might have induced the relatively low REE at six months. Thus, further investigations involving a large sample size and REE data with a stable thyroid function after treatment should be conducted to establish the optimal nutritional intervention for patients with Graves' disease during treatment.

Body weight loss has been described in previous studies of hyperthyroidism $(35,36)$. Established body composition evaluation techniques in a previous study showed that the loss of bone mineral content and MM was predominant in typical hyperthyroidism (37). In another study, it was shown that the free-fat mass was more sensitive to thyroid hormones than the body fat mass (38). During treatment, patients who developed hypothyroidism had a larger weight gain than those who did not (6). In the present study, the FM was significantly increased at one and three months but not at six months compared to FM at the start of treatment. The MM and LBM were relatively unchanged at one month but significantly increased at three and six months. There seems to be a delay in the changes to the MM and LBM compared to the FM.

An increase in the FM was associated with an increased risk of metabolic disorders, including diabetes, hypertension and dyslipidemia. To prevent these metabolic disorders, nutritional intervention is imperative during treatment for Graves' disease. A previous study showed that the body weight and FM increased during the transition from a hyperthyroid state to a euthyroid state without any change in the LBM (7). In our study, the body weight increased after treatment with increasing MM and LBM values and no marked change in the FM. These findings suggest that our nutritional guidance based on the measured REE (recommended energy intake between 1.3- and 1.5-fold of the REE) may be not appropriate during treatment for Graves' disease.

However, considerable variation in the FM, MM and LBM was noted in patients at three and six months. This variation can be explained by the variation in patients' dietary intake during treatment. The change in the appetite during treatment for Graves` disease remains unclear. It has been suggested that hyperthyroidism is associated with decreased levels of ghrelin (39). In another study, patients with hyperthyroidism had an increased energy intake covered solely by enhanced carbohydrate consumption, with protein and fat intake relatively unaffected (40). We were unable to include a questionnaire about the appetite and detailed food consumption in the present study, which is a limitation. Further studies including evaluations of the long-term body weight changes and detailed food consumption in more patients are therefore needed.

\section{Conclusion}

The REE was significantly elevated with thyrotoxicosis of Graves' disease and decreased dramatically very early after treatment. The REE and REE/BEE in the patients with Graves' disease were significantly higher at the onset and significantly lower at six months after treatment than in healthy control, which may lead to weight gain. The REE/ BEE ratio, a clinical stress factor in patients with Graves' disease, was about 1.6-fold during the first month and normalized during treatment to 1.0 -fold. However, this dramatic reduction might be affected by overtreatment. There was a delay in the increase in the MM and LBM values compared to the FM. Considering the change in energy consumption, nutritional intervention is necessary for patients with Graves' disease during treatment. Further prospective studies including a questionnaire about appetite and food consumption are needed in order to demonstrate the optimal nutritional intervention.

\section{The authors state that they have no Conflict of Interest (COI).}

\section{Financial Support}

This study was funded by a Grant-in-Aid from Kitasato University Medical School to MS.

\section{References}

1. Hoogwerf BJ, Nuttall FQ. Long-term weight regulation in treated hyperthyroid and hypothyroid subjects. Am J Med 76: 963-970, 1984.

2. Lonn L, Stenlof K, Ottosson M, Lindroos AK, Nystrom E, Sjostrom L. Body weight and body composition changes after treatment of hyperthyroidism. J Clin Endocrinol Metab 83: 42694273, 1998.

3. Crooks J, Murray IP, Wayne EJ. Statistical methods applied to the clinical diagnosis of thyrotoxicosis. Q J Med 28: 211-234, 1959.

4. Berg G, Michanek A, Holmberg E, Nystrom E. Clinical outcome of radioiodine treatment of hyperthyroidism: a follow-up study. J Intern Med 239: 165-171, 1996.

5. Jansson S, Berg G, Lindstedt G, Michanek A, Nystrom E. Overweight--a common problem among women treated for hyperthyroidism. Postgrad Med J 69: 107-111, 1993.

6. Dale J, Daykin J, Holder R, Sheppard MC, Franklyn JA. Weight gain following treatment of hyperthyroidism. Clin Endocrinol (Oxf) 55: 233-239, 2001.

7. Chng CL, Lim AY, Tan HC, et al. Physiological and metabolic changes during the transition from hyperthyroidism to euthyroidism in Graves' disease. Thyroid 26: 1422-1430, 2016.

8. Harris JA, Benedict FG. A biometric study of human basal metabolism. Proc Natl Acad Sci U S A 4: 370-373, 1918.

9. Inoue $\mathrm{M}$, Hayashi $\mathrm{A}$, Taguchi $\mathrm{T}$, et al. Effects of canagliflozin on body composition and hepatic fat content in type 2 diabetes patients with non-alcoholic fatty liver disease. J Diabetes Investig 10: 1004-1011, 2019.

10. Leahy S, O’Neill C, Sohun R, Jakeman P. A comparison of dual energy X-ray absorptiometry and bioelectrical impedance analysis 
to measure total and segmental body composition in healthy young adults. Eur J Appl Physiol 112: 589-595, 2012.

11. Boothby WM, Sandiford I. Summary of the basal metabolism data on 8614 subjects with especial reference to the normal standards for the estimation of the basal metabolic rate. J Biol Chem $\mathbf{5 4}$ 783-803, 1922.

12. Reeves MM, Capra S. Predicting energy requirements in the clinical setting: are current methods evidence based? Nutr Rev 61: 143-151, 2003.

13. Dauncey MJ. Thyroid hormones and thermogenesis. Proc Nutr Soc 49: 203-215, 1990.

14. Silva JE. Thyroid hormone control of thermogenesis and energy balance. Thyroid 5: 481-492, 1995.

15. Freake HC, Oppenheimer JH. Thermogenesis and thyroid function Annu Rev Nutr 15: 263-291, 1995.

16. Tata JR. The road to nuclear receptors of thyroid hormone. Biochim Biophys Acta 1830: 3860-3866, 2013.

17. Tata JR, Ernster L, Lindberg O. Control of basal metabolic rate by thyroid hormones and cellular function. Nature 193: 1058-1060, 1962.

18. Tata JR, Ernster L, Lindberg O, Arrhenius E, Pedersen S, Hedman $\mathrm{R}$. The action of thyroid hormones at the cell level. Biochem J 86 408-428, 1963.

19. Danforth E Jr. The role of thyroid hormones and insulin in the regulation of energy metabolism. Am J Clin Nutr 38: 1006-1017, 1983.

20. Harper ME, Seifert EL. Thyroid hormone effects on mitochondrial energetics. Thyroid 18: 145-156, 2008

21. Flier JS, Harris M, Hollenberg AN. Leptin, nutrition, and the thyroid: the why, the wherefore, and the wiring. J Clin Invest $\mathbf{1 0 5}$ 859-861, 2000

22. Zimmermann-Belsing T, Brabant G, Holst JJ, Feldt-Rasmussen U. Circulating leptin and thyroid dysfunction. Eur J Endocrinol 149: 257-271, 2003.

23. Sesmilo G, Casamitjana R, Halperin I, Gomis R, Vilardell E. Role of thyroid hormones on serum leptin levels. Eur J Endocrinol 139: 428-430, 1998

24. Tagliaferri M, Berselli ME, Calo G, et al. Subclinical hypothyroidism in obese patients: Relation to resting energy expenditure, serum leptin, body composition, and lipid profile. Obes Res 9: 196201, 2001

25. Moulin de Moraes CM, Mancini MC, de Melo ME, et al. Prevalence of subclinical hypothyroidism in a morbidly obese population and improvement after weight loss induced by Roux-en-Y gastric bypass. Obes Surg 15: 1287-1291, 2005.

26. Bastemir M, Akin F, Alkis E, Kaptanoglu B. Obesity is associated with increased serum TSH level, independent of thyroid function. Swiss Med Wkly 137: 431-434, 2007.

27. Knudsen N, Laurberg P, Rasmussen LB, et al. Small differences in thyroid function may be important for body mass index and the occurrence of obesity in the population. J Clin Endocrinol Metab 90: 4019-4024, 2005.

28. Imaizumi M, Akahoshi M, Ichimaru S, et al. Risk for ischemic heart disease and all-cause mortality in subclinical hypothyroidism. J Clin Endocrinol Metab 89: 3365-3370, 2004.

29. Yildirimkaya M, Ozata M, Yilmaz K, Kilinc C, Gundogan MA, Kutluay T. Lipoprotein(a) concentration in subclinical hypothyroidism before and after levo-thyroxine therapy. Endocr J 43: 731736, 1996.

30. Danese MD, Ladenson PW, Meinert CL, Powe NR. Clinical review 115: effect of thyroxine therapy on serum lipoproteins in patients with mild thyroid failure: a quantitative review of the literature. J Clin Endocrinol Metab 85: 2993-3001, 2000.

31. Michalopoulou G, Alevizaki M, Piperingos G, et al. High serum cholesterol levels in persons with 'high-normal' TSH levels: should one extend the definition of subclinical hypothyroidism? Eur J Endocrinol 138: 141-145, 1998.

32. Arem R, Escalante DA, Arem N, Morrisett JD, Patsch W. Effect of L-thyroxine therapy on lipoprotein fractions in overt and subclinical hypothyroidism, with special reference to lipoprotein(a). Metabolism 44: 1559-1563, 1995

33. Reinehr T, de Sousa G, Andler W. Hyperthyrotropinemia in obese children is reversible after weight loss and is not related to lipids. J Clin Endocrinol Metab 91: 3088-3091, 2006.

34. Watson LP, Raymond-Barker P, Moran C, et al. An approach to quantifying abnormalities in energy expenditure and lean mass in metabolic disease. Eur J Clin Nutr 68: 234-240, 2014.

35. Blahd WH, Hays MT. Graves' disease in the male. A review of 241 cases treated with an individually calculated dose of sodium iodide I 131. Arch Intern Med 129: 33-40, 1972.

36. Williams RH. Thiouracil treatment of thyrotoxicosis; the results of prolonged treatment. J Clin Endocrinol Metab 6: 1-22, 1946.

37. Bayley TA, Harrison JE, McNeill KG, Mernagh JR. Effect of thyrotoxicosis and its treatment on bone mineral and muscle mass. $\mathrm{J}$ Clin Endocrinol Metab 50: 916-922, 1980.

38. Edmonds CJ, Smith T. Total body potassium in relation to thyroid hormones and hyperthyroidism. Clin Sci (Lond) 60: 311-318, 1981.

39. Riis AL, Hansen TK, Moller N, Weeke J, Jorgensen JO. Hyperthyroidism is associated with suppressed circulating ghrelin levels. J Clin Endocrinol Metab 88: 853-857, 2003.

40. Pijl H, de Meijer PH, Langius J, et al. Food choice in hyperthyroidism: potential influence of the autonomic nervous system and brain serotonin precursor availability. J Clin Endocrinol Metab 86: 5848-5853, 2001.

The Internal Medicine is an Open Access journal distributed under the Creative Commons Attribution-NonCommercial-NoDerivatives 4.0 International License. To view the details of this license, please visit (https://creativecommons.org/licenses/ by-nc-nd/4.0/).

(C) 2020 The Japanese Society of Internal Medicine

Intern Med 59: 1827-1833, 2020 